\title{
Effect of Thermoplastic Incorporation on the Performance of Thermosetting Matrix
}

\author{
R. Ollier, A. Stocchi, E. Rodriguez, V. Alvarez ${ }^{*}$ \\ Composite Materials Group, Materials Science and Technology Research Institute (INTEMA), University of Mar del Plata-Na- \\ tional Research Council (CONICET), Mar del Plata, Argentina. \\ Email: *alvarezvera@fi.mdp.edu.ar
}

Received January 29 ${ }^{\text {th }}, 2012$; received March $10^{\text {th }}$, 2012; accepted May $1^{\text {st }}, 2012$

\begin{abstract}
In this work, the morphology, thermal and viscoelastic properties, deformation and fracture behaviour of a commercial vinylester resin modified with a biodegradable polymer was investigated. Flexural, impact and fracture tests were performed on the blends with different polycaprolactone (PCL) contents. They exhibited improved stiffness and fracture properties in comparison to the neat resin. From SEM analysis of fracture surfaces, stress whitening and branced fracture paths toughening mechanisms were identified. The dependence of the glass transition temperature with PCL content was adequately fitted by simple models available in the literature. From the results of these models along with the results of calorimetric studies and SEM analysis, it can be concluded that the interaction between vinylester and PCL is strong enough to avoid phase separation.
\end{abstract}

Keywords: Polymer Matrix Composites; Mechanical Properties; Fracture

\section{Introduction}

The vinylester resins (VE) are thermosets widely used in several industrial applications. The main advantages of this material are the good chemical resistance, thermal stability and mechanical strength. In addition, its low viscosity makes it very attractive for liquid composite moulding techniques as RTM (resin transfer moulding) and VARTM (vacuum assisted resin transfer moulding). However, vinylester has low ductility and poor fracture toughness, which limits its use as an engineering material [1].

The most widely used methods to toughen thermosetting resins are the incorporation of rubber and inorganic particles [2]. Rubber toughening can lead to a significant increase in toughness, but this method usually leads to a decrease in the material's stiffness and strength, which may be undesirable in many applications. Toughening with inorganic fillers, on the other hand, can result in a more modest improvement of toughness but without significant loss of strength and even with an improvement in modulus [3].

The blending of a thermosetting matrix with a thermoplastic polymer that phase separates during the cure circle of the matrix is an alternative approach for toughening thermoset polymers [4,5]. In general, the thermoplastic phase has good thermal stability and low water uptake

${ }^{*}$ Corresponding author. compared with rubbers [6]. Various types of thermoplastics have been explored in order to modify thermoset resins. It has been indicated that the modifications need a fine phase separated structure and a good adhesion between the two separated phases to achieve fracture toughness improvements [7].

Polycaprolactone (PCL) is a synthetic biodegradable polymer. It is a linear, hydrophobic and partially crystalline polyester that can be slowly consumed by microorganisms [8]. Its physical properties and commercial availability make it very attractive as a substitute for non biodegradable polymers [9]. The main limitation of PCL is its low melting temperature $\left(T_{m}=65^{\circ} \mathrm{C}\right)$, which can be overcome by blending it with other polymers making it very appropriate for fracture toughness improvement [10].

However, this fact can be used for special purposes. Thermal mending of polymer composites is a major interesting area. The thermoset/thermoplastic blend allows the possibility of obtaining a material with good load bearing capability, given by the thermoset, fracture toughness improvement, given by the thermoplastic, and this thermal "healing" possibility after a curing cycle when the material is damaged, that is a synergic effect [11].

In this work a thermoplastic polymer (PCL) was added to a brittle matrix (VE) in order to improve its toughness. For this purpose, blends with different PCL contents were prepared and the morphology, thermal properties 
and mechanical properties were determined and analyzed. It is tough that the systems studied here could have thermal mending capability which will be analyzed in a future work.

\section{Experimental Details}

\subsection{Materials}

A commercial available vinylester resin (VE; Derakane 411 - 350 Momentum; Ashland) was used as a thermoset matrix and Metil Etil Ketone Peroxide (MEKP; Médano) was used as catalyst. Polycaprolactone (PCL), Mn = $42.500 \mathrm{gr} / \mathrm{mol}$, was obtained from Sigma Aldrich. All materials were used as received.

\subsection{Sample Preparation}

The thermoset resin was heated to $100^{\circ} \mathrm{C}$ with constant stirring (600 - $720 \mathrm{rpm}$ ). After that, the PCL was slowly added in different weight ratios varying from 0 to 36 $w t \%$, that was the maximum amount that could be possible dissolved without the formation of aggregates. After 30 minutes, total dissolution of the PCL was achieved. The temperature was reduced to $60^{\circ} \mathrm{C}$ and the catalyst was quickly added to the mixture in a $1 \%$ wt referred to the resin. The final catalyst weight ratios in the blends were $1 \%, 0.9 \%, 0.8 \%, 0.76 \%, 0.72 \%, 0.68 \%$ and $0.64 \%$. Finally, plaques of $6 \mathrm{~mm}$ thickness were obtained in an aluminum mould.

Samples were cured in an oven. The curing cycle consisted in 1 hour at $50^{\circ} \mathrm{C}$ in order to eliminate bubbles, followed by 2 hours at $110^{\circ} \mathrm{C}$ as a procuring cycle.

Blends of increasing PCL wt\% were named as VE for 100\%VE and respectively until VE64 (64\%VE + 36\% PCL).

\subsection{Mechanical Properties}

Fracture characterization was carried out in three-pointbending configuration in an Instron dynamometer 4467 at a crosshead speed of $1 \mathrm{~mm} / \mathrm{min}$ in accordance with ASTM 5045-93 standard recommendations. Critical stress intensity factor $\left(K_{I C}\right)$ values and energy release rate $\left(G_{I C}\right)$ values were obtained from these tests. Single-edge notched bend SENB specimens were cut out from thick plaques $(B=5 \mathrm{~mm})$. Sharp notches were introduced by sliding a fresh razor blade into a machined slot. Crack-to-depth $(a / W)$, thickness-to-depth $(B / W)$ and span-to-depth $(S / W)$ ratios were kept equal to $0.5,0.5$ and 4 , respectively.

Fracture surfaces of specimens broken in fracture tests were also analyzed by scanning electron microscopy (SEM, model JEOL JSM 6460 LV) after they had been coated with a thin layer of gold.

Differential scanning calorimetry (DSC) analysis was performed for the different materials in a Perkin Elmer
Pyris 1DSC analyzer. Samples were heated from $-65^{\circ} \mathrm{C}$ up to $200^{\circ} \mathrm{C}$ at a rate of $10 / \mathrm{min}$. This study was carried out in order to verify the possible existence of phase separation.

Viscoelastic properties were measured using a dynamic mechanical analyzer Perkin Elmer DMA 7e with three-point-bending geometry. Tests were performed in temperature scan mode from $20^{\circ} \mathrm{C}$ to $180^{\circ} \mathrm{C}$ at a fixed frequency of $1 \mathrm{~Hz}$ and a heating rate of $10^{\circ} \mathrm{C} / \mathrm{min}$. Rectangular specimens having a size of $20 \mathrm{~mm} \times 3.5 \mathrm{~mm} \times 2$ $\mathrm{mm}$ were used for the evaluation of storage modulus $\left(E^{\prime}\right)$, loss modulus ( $E ")$ and damping parameter $(\tan \delta)$. The static stress was $500 \mathrm{MPa}$ and dynamic stress $300 \mathrm{MPa}$.

Flexural tests were done in accordance with ASTMD 790-03 standard over samples of $10 \mathrm{~mm} \times 5 \mathrm{~mm} \times 100$ $\mathrm{mm}$ in an Instron dynamometer 4467 at a crosshead speed of $1 \mathrm{~mm} / \mathrm{min}$, and the span used was $80 \mathrm{~mm}$. Flexural modulus was determined from the initial slope load-displacement plot.

Izod tests were also conducted on notched specimens according to ASTM D256-04 at $1 \mathrm{~m} / \mathrm{s}$ in a falling weight Fractovis of CEAST. Impact strength values were obtained from numerical integration of the load-displacement records and they were normalized to the unnotched ligament area.

\section{Results and Discussion}

\subsection{Dynamical-Mechanical Characterization}

Figure 1 shows the damping factor $(\tan \delta)$ as a function of temperature for blends with different compositions. It is clear that the $\tan \delta$ peak was shifted to lower temperatures when PCL content was increased. From this peak, $T_{g}$ was determined. Figure 2 summarizes the glass transition temperature, $T_{g}$, of each system as a function of PCL content. As it can be observed form the previous figure, the $T_{g}$ of the vinylester resin decreased as a function of thermoplastic content. This result is in accordance with other thermoset-thermoplastic bleds reported in the literature [12].

There are several models $[13,14]$ available in literature to correlate the $T_{g}$ of blends. One of them is Fox equation [13] that, for a binary system $1+2$, can be represented by:

$$
\frac{1}{T_{g}}=\frac{x_{1}}{T_{g 1}}+\frac{1-x_{1}}{T_{g 2}}
$$

where $T_{g}$ is referred to the glass transition temperature of the blend, $T_{g, i}$ to pure component $i$, and $x_{i}$ is the weight fraction of one component. Fox equation does not take in account the interaction between the blend components and therefore it did not fit the experimental data obtained.

Gordon-Taylor (GT) equation is useful to predict the 


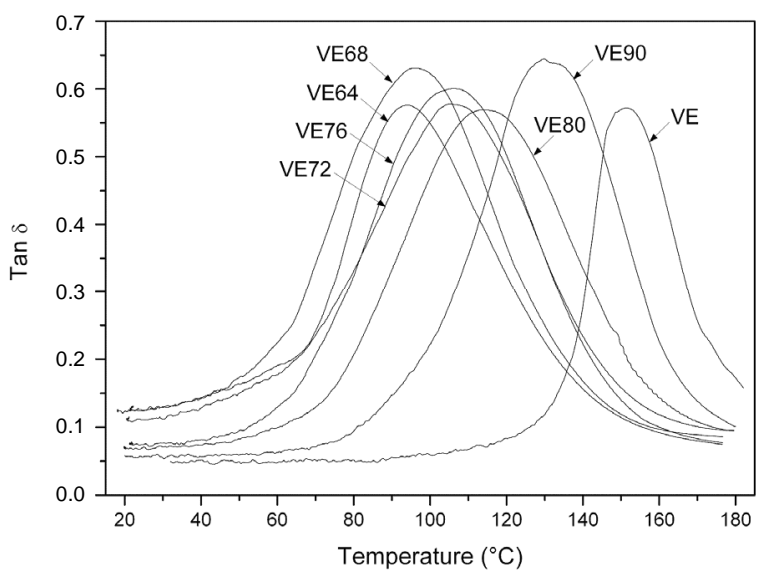

Figure 1. Damping factor $(\tan \delta)$ as a function of temperature for blends with different compositions.

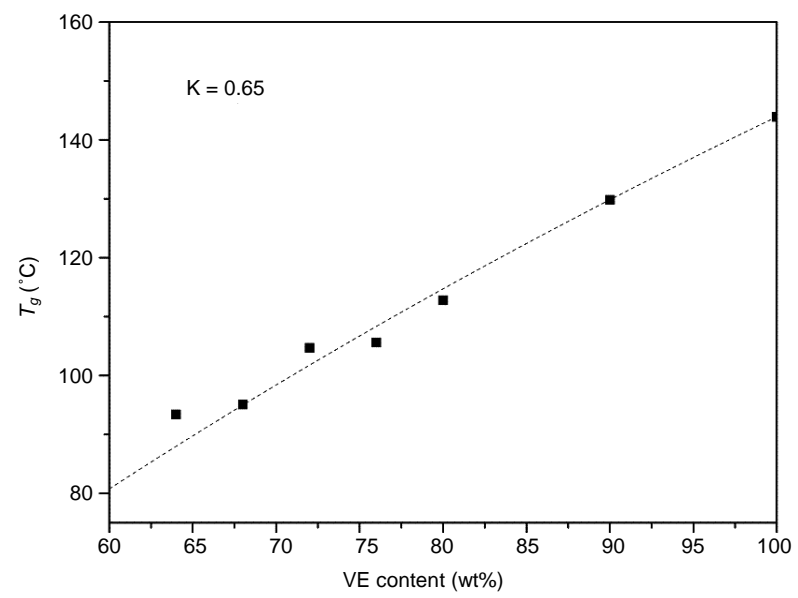

Figure 2. $T_{g}$ as a function of VE content. Points indicate experimental values and line represent the model prediction.

$T_{g}$ of a blend based on the interaction between the components [14]. The glass transition temperature of the blend can be written by the GT equation as follows:

$$
T_{g}=\frac{W_{1} T_{g 1}+k W_{2} T_{g 2}}{W_{1}+k W_{2}}
$$

where $T_{g}$ is the glass transition temperature of the blend, $T_{g 1}$ and $T_{g 2}$, are the glass transition temperatures of the components 1 and 2, respectively, $W$ is the weight fraction of the components and $k$ is a constant. The curve in Figure 2 was drawn using Gordon-Taylor equation obtaining a $k$ value of 0.65 and showing a good correlation with experimental data. Several authors [15-17] have suggested that $k$ can be taken as a fitting parameter that measures the strength of the interaction between the components of the blend. Belorgey, and Prud'homme [15], modelled the change in $T_{g}$ with composition of poly (e-caprolactone) with chlorinated polyethylene, poly (vinyl chloride) (PVC) and chlorinated PVC. They found values of k varying from 0.26 to 1.0 . When this approach is used, a $k$ value of 0.26 suggests a weak interaction whereas a $k$ value of 1.0 suggests an important interaction.

In our case, the $k$ value of 0.65 suggests intermediate interaction. This fact along with the transparency observed in all systems suggests that no phase separation occurred.

The morphology of the blends was studied by several methods. DSC analysis showed only one $T_{g}$ peak, and no melting peak of PCL was observed, suggesting that only one phase is present in the blend. Furthermore, fracture surfaces of samples broken in SENB tests were treated with chloroform during 15 minutes and observed with an optical microscope and SEM. Chloroform dissolves PCL and in case of phase separation it reveals the surface microstructure. In both cases no evidence of phase separation was found.

Figure 3 shows the storage modulus $E^{\prime}$ values as a function of temperature for the different materials. As it can be observed in this figure, a sharp drop of $E$ ' in a small range of temperature was displayed for all systems, indicating the presence of the $T_{g}$. As the amount of second phase was increased, the drop became less abrupt. A marked decrease in the storage modulus as function of the polycaprolactone in the blend was also noted.

\subsection{Mechanical Characterization}

Experimental values of flexural modulus as a function of polycaprolactone content are presented in Figure 4.

As it may be clearly observed, increasing polycaprolactone presence significantly affects the flexural properties of the vinylester matrix. These results are in accordance with previous results [17].

The reduction of flexural modulus exhibited by specimens as function of thermoplastic content is in accordance with the results of storage modulus presented in Figure 3.

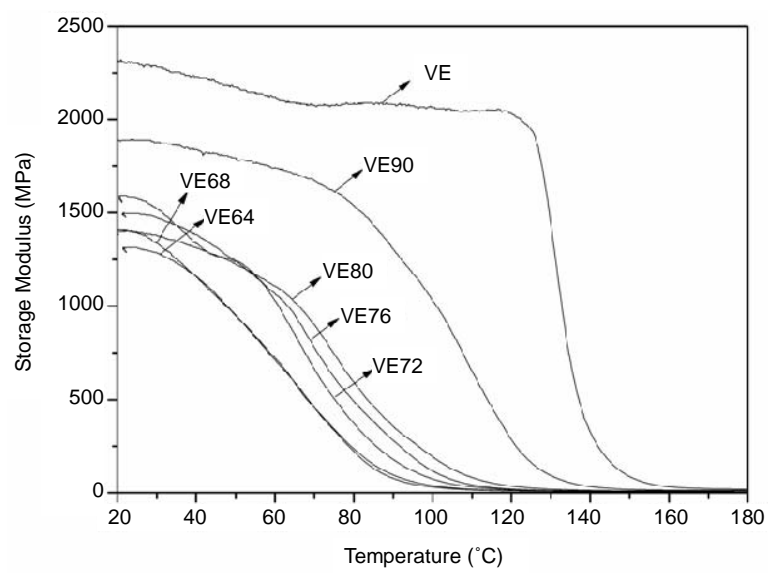

Figure 3. Storage modulus ( $\left.E^{\prime}\right)$ as a function of temperature for blends with different compositions. 


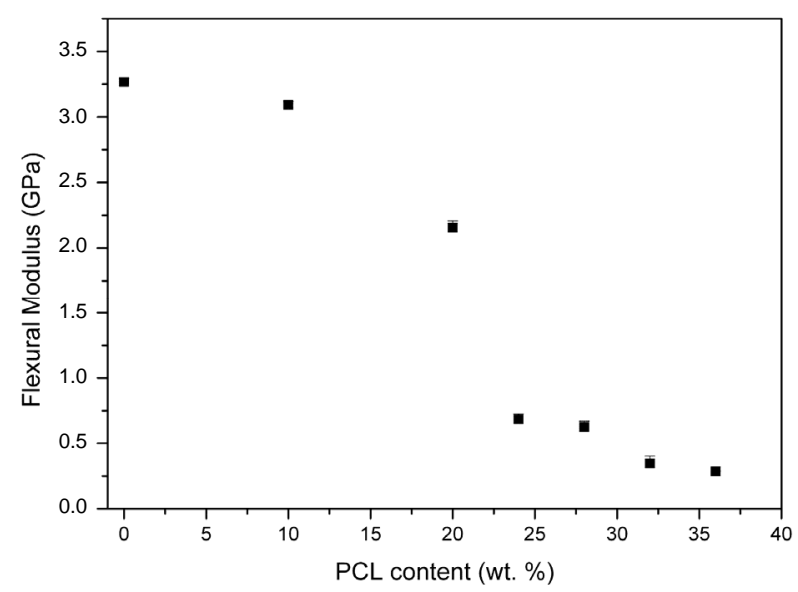

Figure 4. Flexural modulus of VE-PCL systems as a function of PCL content.

\subsection{Fracture Characterization}

Critical stress intensity factor $\left(K_{I C}\right)$ and energy release rate $\left(G_{I C}\right)$ values of VE-PCL blends are presented in Figures 5 and 6 respectively along with their deviations. In these figures, it can be observed that modifying the VE with PCL results in an increase in fracture toughness. $K_{I C}$ monotonically increased with polycaprolactone content until 28 wt.\% whereas a maximum in $\left(G_{I C}\right)$ was found around 32 wt.\% of polycaprolactone added. It should be also noted that all composites exhibited fracture toughness values significantly higher than that of the vinylester matrix, reaching an increase in $K_{I C}$ as high as $240 \%$ for the blend with 28 wt.\% PCL. This result is in accordance with the literature. Yang et al. [12] have reported an important increase in $K_{I C}$ with the incorporation of a thermoplastic copolymer. Nimura et al. [18] also reported an increase of 2.5 times on $K_{I C}$ of an epoxy resin modified with a thermoplastic polymer.

Scanning electron microscopy of the fracture surfaces of specimens broken in fracture tests show that the pure vinylester matrix (VE) presents a flat fracture surfaces as seen in Figures 7. The only remarkable features are low ridges and shallow grooves. The observed morphology is indicative of a brittle fracture [19] and it is typical of thermoset systems [6]. For the 90 wt.\% VE blend (VE90; Figure 7(b)) the fracture surface was quite similar, indicating just little plastic deformation in accordance with the low increase on the fracture energy found [18].

As the PCL content increased, a change in the failure mode was observed, switching to stable crack propagation and a plastic failure mode was found. Plastic deformation features can be observed for VE80 (Figure 7(c)) and VE64 (Figure 7(d)) systems. Peaks and fibril structures were clear, stress whitening also indicates new energy absorption mechanisms present in the blends. Finally the branced fracture paths results in high energy absorption [19].

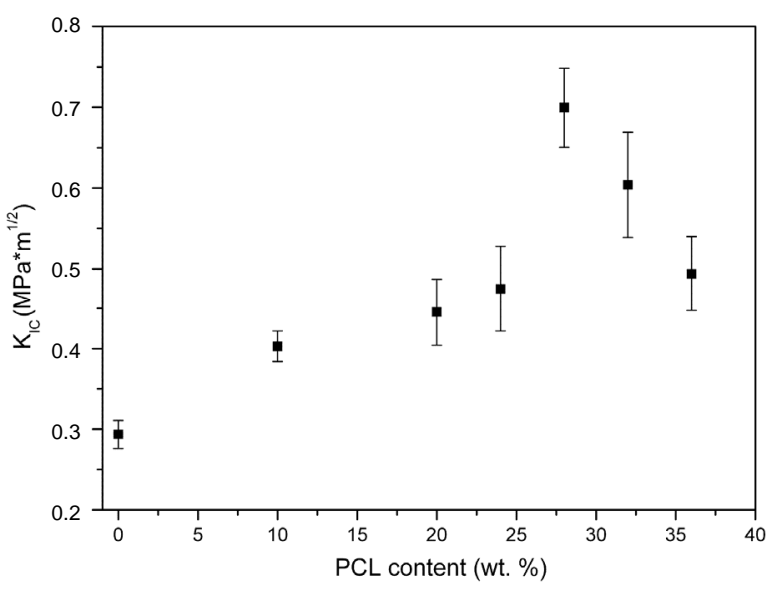

Figure 5. Critical stress intensity factor $\left(K_{I C}\right)$ of VE-PCL systems as a function of PCL content.

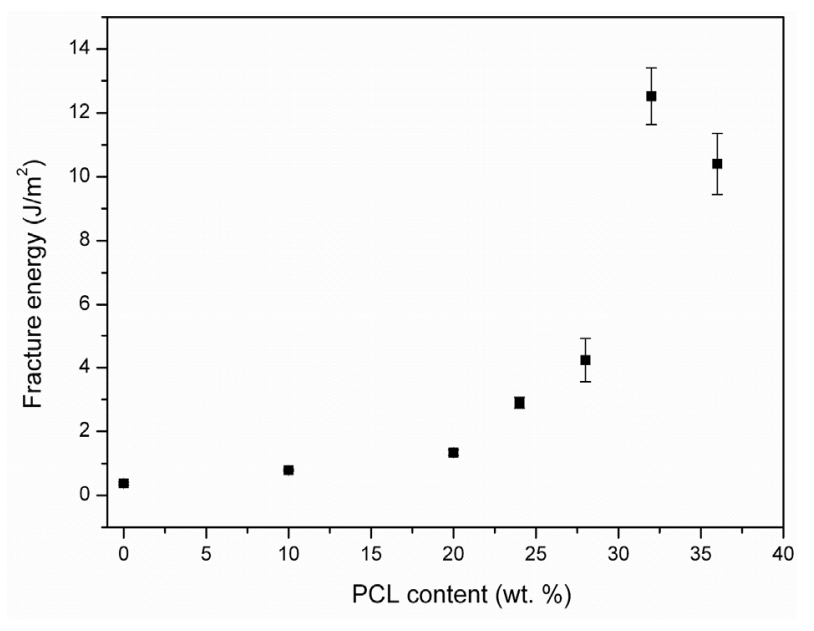

Figure 6. Energy release rate $\left(G_{I C}\right)$ of VE-PCL systems as a function of PCL content.

\subsection{Impact Properties}

Figure 8 shows the experimental values of impact energy as a function of thermoplastic content. As it may be clearly observed in this figure, the addition of PCL significantly affects the impact behaviour of vinylester matrix [20].

In agreement with the fracture patterns observed in SEM, impact properties were improved by the second phase addition, mainly due to the presence of energy absorption mechanisms such as branced fracture paths and plastic deformation.

\section{Conclusions}

In this work, the morphology, thermal and viscoelastic properties, deformation and fracture behaviour of a commercial vinylester resin modified with a biodegradable polymer was investigated.

From Dynamical-mechanical characterization a $T_{g}$ de 


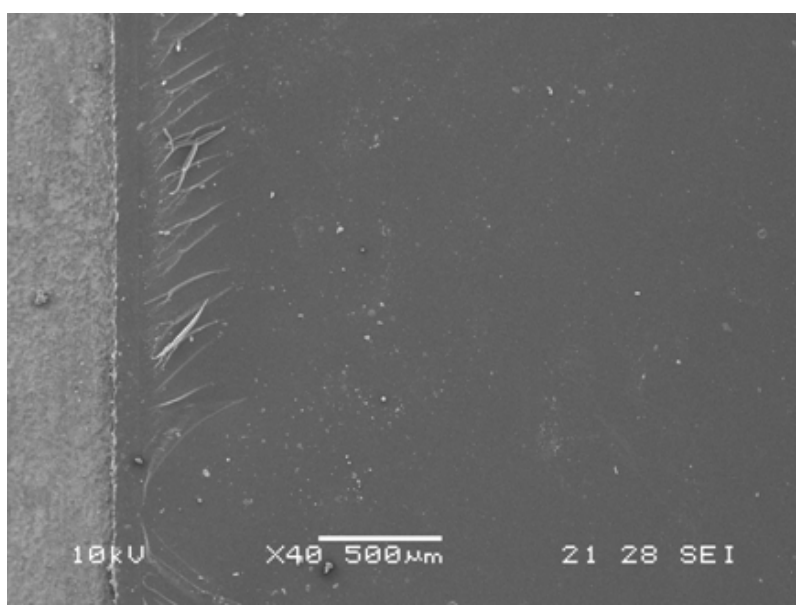

(a)

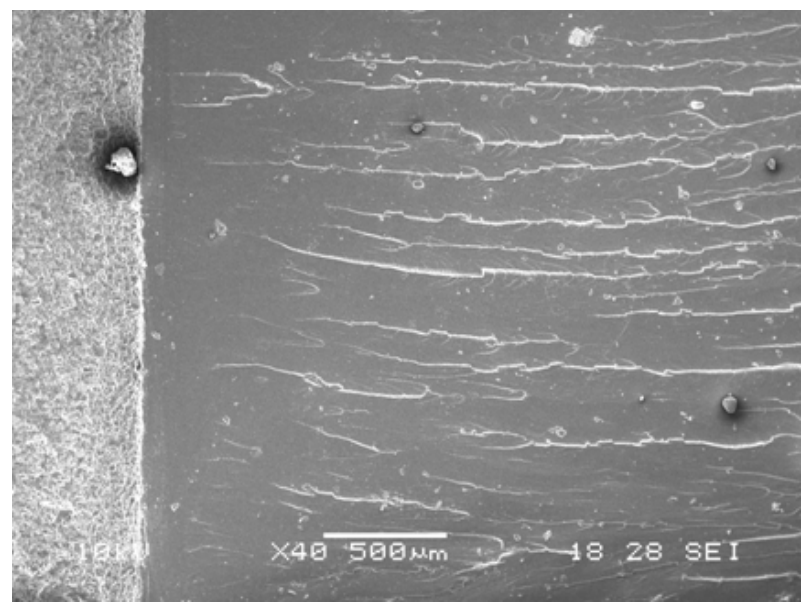

(c)

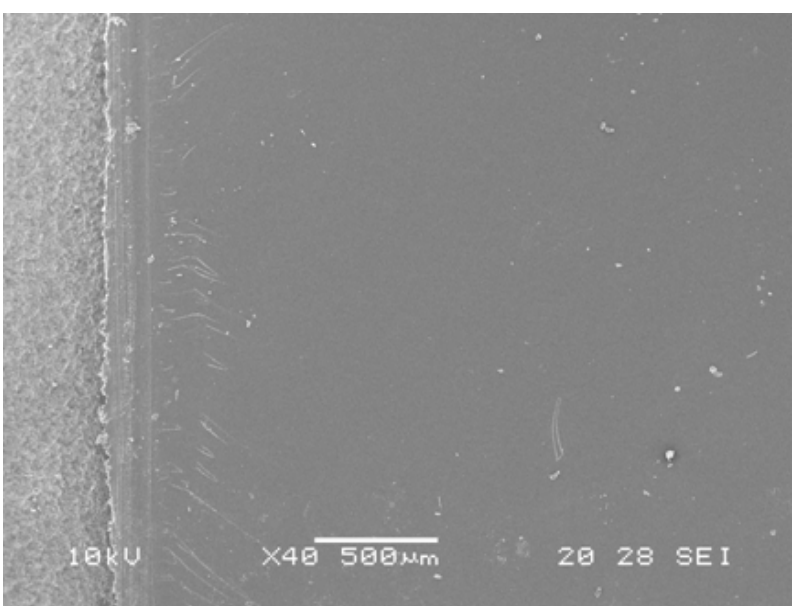

(b)

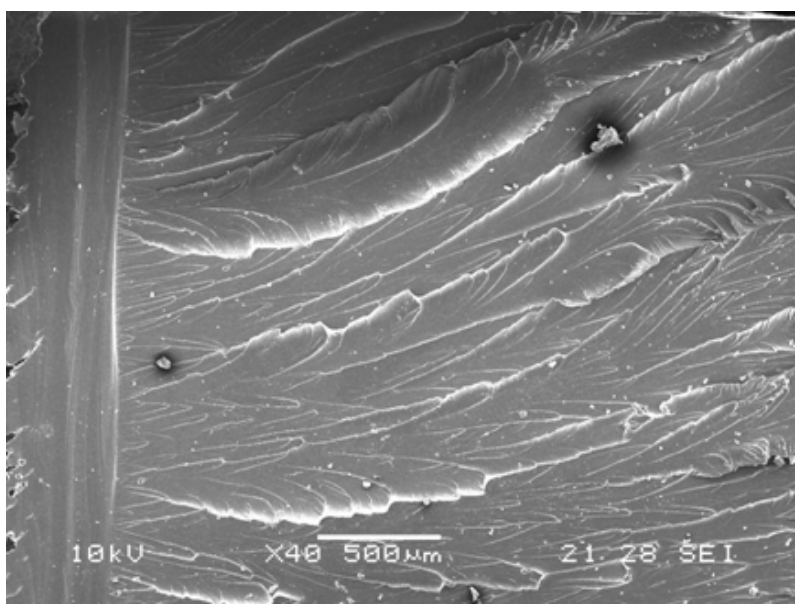

(d)

Figure 7. Scanning electron microscopy of fracture surfaces of different VE-PCL blends: (a) VE; (b) VE90; (c) VE80; (d) VE64.

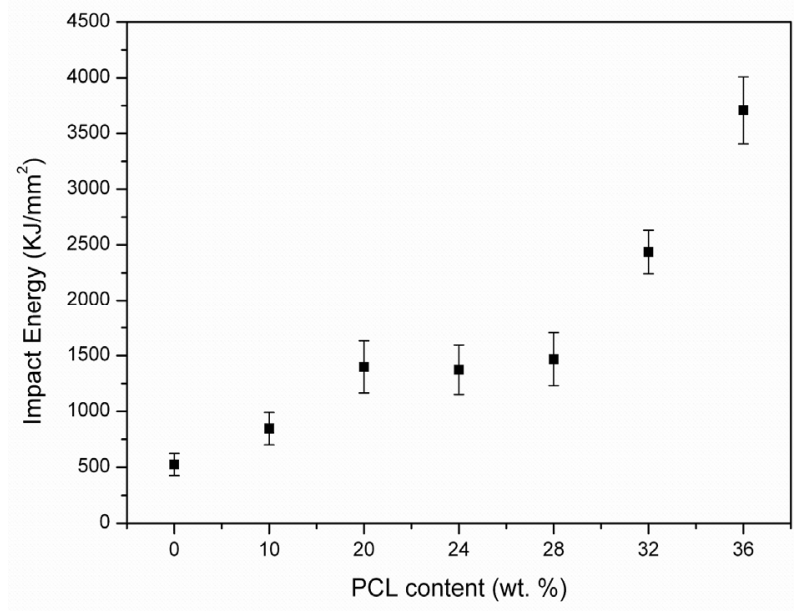

Figure 8. Experimental values of impact energy of VE-PCL systems as a function of thermoplastic content.

crease of the vinylester resin as a function of thermoplastic content was found.
Gordon-Taylor model was used to fit the experimental $T_{g}$ data obtained by DMA. It was observed that the interaction parameter $\mathrm{k}$ was 0.65 , suggesting interaction between the components of the blend. The morphology of the blends was observed by several methods and in all cases no evidence of phase separation was found. From flexural tests, it was found that increasing polycaprolactone presence significantly decreases the flexural properties of the vinylester matrix.

Critical stress intensity factor $\left(K_{I C}\right)$ and energy release rate $\left(G_{I C}\right)$ for the matrix and the blends were obtained. All blends exhibited fracture toughness values significantly higher than that of the vinylester matrix, reaching an increase in $K_{I C}$ as high as $240 \%$ for the blend with 28 wt.\% PCL. This fact was confirmed by the SEM analysis of the fracture surfaces. Energy absorption mechanisms such as branched patterns and stress whitening were observed for the blends with the increasing of PCL content. Impact properties were also improved by the incorporation of PCL to the blends. 
As a general conclusion, it can be said that blends based on a commercial thermosetting polymer and a biodegradable thermoplastic polymer, lead to a blend with improved fracture and impact properties without a significant loss of thermal properties.

\section{Acknowledgements}

The authors acknowledge to the National Research Council of Argentina (CONICET), the ANPCyP and the National University of Mar del Plata (UNMdP) for the financial support.

\section{REFERENCES}

[1] E. J. Robinette, S. Ziaee and G. R. Palmese, “Toughening of Vinyl Ester Resin Using Butadiene-Acrylonitrile Rubber Modifiers,” Polymer, Vol. 45, No. 18, 2004, pp. 61436154. doi:10.1016/j.polymer.2004.07.003

[2] J. Lee and A. F. Yee, "Inorganic Particle Toughening I: Micro-Mechanical Deformations in the Fracture of Glass Bead Filled Epoxies,” Polymer, Vol. 42, No. 2, 2001, pp. 577-588. doi:10.1016/S0032-3861(00)00397-9

[3] T. Kawaguchi and R. A. Pearson, "The Effect of ParticleMatrix Adhesion on the Mechanical Behavior of Glass Filled Epoxies. Part 2. A Study on Fracture Toughness,” Polymer, Vol. 44, No. 15, 2003, pp. 4239-4247. doi:10.1016/S0032-3861(03)00372-0

[4] J. P. Pascault and R. J. J. Williams, "Polymer Blends Volume 1: Formulation,” John Wiley and Sons, New York, 2000.

[5] S. Pham and P. J. Burchill, "Toughening of Vinyl Ester Resins with Modified Polybutadienes,” Polymer, Vol. 36, No. 17, 1995, pp. 3279-3285. doi:10.1016/0032-3861(95)99426-U

[6] B. B. Johnsen, A. J. Kinloch and A. C. Taylor, "Toughness of Syndiotactic Polystyrene/Epoxy Polymer Blends: Microstructure and Toughening Mechanisms," Polymer, Vol. 46, No. 18, 2005, pp. 7352-7369. doi:10.1016/j.polymer.2005.05.151

[7] X. Song, S. Zheng, J. Huang, P. Zhu and Q. Guo, "Miscibility, Morphology and Fracture Toughness of Tetrafunctional Epoxy Resin/Poly (Styrene-co-Acrylonitrile) Blends,” Journal of Materials Science, Vol. 35, No. 22, 2000, pp. 5613-5619. doi:10.1023/A:1004824628535

[8] J. K. Pandey, K. R. Reddy, A. P. Kumar and R. P. Singh, "An Overview on the Degradability of Polymer Nanocomposites," Polymer Degradation and Stability, Vol. 88, No. 2, 2005, pp. 234-250.

doi:10.1016/j.polymdegradstab.2004.09.013

[9] P. Dubois, C. Jacobs, R. Jerome, P. Teyssie, "Macromolecular Engineering of Polylactones and Polylactides. 4. Mechanism and Kinetics of Lactide Homopolymerization by Aluminum Isopropoxide,” Macromolecules, Vol. 24,
No. 9, 1991, pp. 2266-2270. doi:10.1021/ma00009a022

[10] C. De Kesel, C. V. Wauven and C. David, "Biodegradation of Polycaprolactone and Its Blends with Poly(Vinylalcohol) by Micro-Organisms from a Compost of HouseHold Refuse,” Polymer Degradation and Stability, Vol. 55, No. 1, 1997, pp. 107-113. doi:10.1016/0141-3910(95)00138-7

[11] X. Luo, R. Ou, D. E. Eberly, A. Singhal, W. Viratyaporn and P. T. Mather, "A Thermoplastic/Thermoset Blend Exhibiting Thermal Mending and Reversible Adhesion," ACS Applied Materials \& Interfaces, Vol. 1, No 3, 2009, pp. 612-620. doi:10.1021/am8001605

[12] X. Yang, F. Yi, Z. Xin and S. Zheng, "Morphology and Mechanical Properties of Nanostructured Blends of Epoxy Resin with Poly(Caprolactone)-Block-Poly(Butadiene-co-Acrylonitrile)-Block-Poly(Caprolactone) Triblock Copolymer," Polymer, Vol. 50, No. 16, 2009, pp. 40894100. doi:10.1016/j.polymer.2009.06.030

[13] T. G. Fox, "Influence of Diluent and of Copolymer Composition on the Glass Temperature of a Polymer System," Bulletin of the American Physical Society, Vol. 1, 1956, p. 123.

[14] M. Gordon and J. S. Taylor, "Ideal Copolymers and the Second-Order Transitions of Synthetic Rubbers. I. NonCrystalline Copolymers," Journal of Applied Chemistry, Vol. 2, No. 9, 1952, pp. 493-500. doi:10.1002/jctb.5010020901

[15] G. Bélorgey, M. Aubin and R. E. Prud'homme, "Studies of Polyester/Chlorinated Poly(Vinyl Chloride) Blends," Polymer, Vol. 23, No. 7, 1982, pp. 1051-1056. doi:10.1016/0032-3861(82)90407-4

[16] G. Bélorgey and R. E. Prud'Homme, "Miscibility of Polycaprolactone/Chlorinated Polyethylene Blends," Journal of Polymer Science: Polymer Physics Edition, Vol. 20, No. 2, 1982, pp. 191-203. doi:10.1002/pol.1982.180200203

[17] P. Huang, S. Zheng, J. Huang, Q. Guo and W. Zhu, “Miscibility and Mechanical Properties of Epoxy Resin/Polysulfone Blends,” Polymer, Vol. 38, No. 22, 1997, pp. 55655571. doi:10.1016/S0032-3861(97)00104-3

[18] K. Mimura, H. Ito and H. Fujioka, “Toughening of Epoxy Resin Modified with in Situ Polymerized Thermoplastic Polymers,” Polymer, Vol. 42, No. 22, 2001, pp. 92239233. doi:10.1016/S0032-3861(01)00460-8

[19] A. B. Cherian, L. A. Varghese and E. T. Thachil, "EpoxyModified, Unsaturated Polyester Hybrid Networks,” European Polymer Journal, Vol. 43, No. 4, 2007, pp. 14601469. doi:10.1016/j.eurpolymj.2006.12.041

[20] F.-L. Jin and S.-J. Park, "Impact-Strength Improvement of Epoxy Resins Reinforced with a Biodegradable Polymer," Materials Science and Engineering: A, Vol. 478, No. 1-2, 2008, pp. 402-405. doi:10.1016/j.msea.2007.05.053 